\title{
Analisis Dampak Produk Domestik Regional Bruto (PDRB) Berdasarkan Harga Konstan Terhadap Pendapatan Masyarakat Kabupaten Bone 2011-2015
}

\author{
Muhammad Sabil \\ Institut Agama Islam Negeri (IAIN BONE) \\ Mashabil96@gmail.com \\ H. Firdaus \\ Sekolah Tinggi Agama Islam (STAI) Al -Furqan Makassar \\ hajifirdaus1994@gmail.com
}

\begin{abstract}
This research is to analyze the Impact of Gross Regional Domestic Product (GRDP) Based on Constant Prices on Community Revenues Bone District 2011-2015. In this study, researchers took 3 samples from 17 sectors in Gross Regional Domestic Products at Constant Prices as populations, namely Agriculture, Forestry, and Fisheries. The reason the researchers took these three samples, because in Bone District were the three superior sectors. Data collection methods used through the documentation method. The data taken was analyzed by Simple Lienear Regression with the help of SPSS 16.0 software. with regression expression $Y=a+b x$. The results of this study indicate that the results of linear regression analysis produce a regression equation $Y=0.984+0.372$, where the constant (a) is 0.984 and the coefficient of the independent variable $(X)$ is 0.372 . Once at GRDP $=0$, then Community Revenue has a value of 0.984 and if GRDP $(X)$ experiences a $1 \%$ increase, then Community Income (Y), will increase by 0.372 to 1.356 as well if GRDP is at 4\% Community Revenue as much as $2.47 \%$. This means that there is a relationship between GDP $(X)$ and Community Income variable $(Y)$ or rejecting the null hypothesis $(\mathrm{HO})$ and accepting the alternative hypothesis $(\mathrm{Ha})$ with a significant level of 0.05 or $5 \%$ where Sig.> 0.05 or tcount <ttable. (Sig. $=0.620>0.05$, or 0.551 $<3.182)$ and the determinant coefficient of $9.2 \%$ or $9 \%$.
\end{abstract}

Keywords: GRDP, Community Revenue

Jurnal Ilmiah Al Tsarwah 


\begin{abstract}
Abstrak
Penilitian ini untuk menganalisis Dampak Produk Domestik Regional Bruto (PDRB) Berdasarkan Harga Konstan Terhadap Pendapatan Masyarakat Kabupaten Bone 2011-2015. Dalam penelitian ini, peneliti mengambil 3 sampel dari 17 sektor dalam Produk Domestik Regional Bruto atas Harga Konstan yang sebagai populasi, yakni Pertanian, Kehutanan, dan Perikanan. Alasan peneliti mengambil ketiga sampel ini, karena di Kabupaten Bone yang paling unggul ke-tiga sektor tersebut. Metode pengumpulan data yang digunakan melalui metode dokumentasi. Data yang diambil dianalisis secara Regresi Lienear Sederhana dengan bantuan software SPSS 16.0. dengan persmaan regresi $Y=a+b x$. Hasil penelitian ini menunjukkan bahwa hasil analisis regresi linear menghasilkan persamaan regresi $Y=0,984+0,372$, dimana konstanta (a) sebesar 0,984 dan koefisien variabel bebas $(X)$ adalah sebesar 0,372. Sehinggah pada saat $P D R B=0$, maka Pendapatan Masyarakat memiliki nilai sebesar 0,984 dan apabila PDRB $(X)$ mengalami kenaikan 1\%, maka Pendapatan Masyarakat (Y), akan mengalami peningkatan sebesar 0,372 menjadi 1,356 begitupun juga jika PDRB berada pada 4\% Pendapatan Masyarakat sebanyak 2,47\%. Artinya adanya hubungan antara variabel PDRB $(X)$ dan variabel Pendapatan Masyarakat $(Y)$ atau menolak hipotesis nol $\left(H_{0}\right)$ dan menerima hipotesis alternatif $\left(H_{a}\right)$ dengan taraf signifikan 0,05 atau 5\% dimana Sig.>0,05 atau thitung < trabel. (Sig. $=0,620>0,05$, atau 0,551<3,182) serta koefisien determinan sebesar $9,2 \%$ atau $9 \%$.
\end{abstract}

Kata Kunci: PDRB, Pendapatan Masyarakat

\title{
PENDAHULUAN
}

Produk Domestik suatu wilayah merupakan nilai seluruh produk dan jasa yang diproduksi di wilayah tersebut tanpa memperhatikan apakah faktor produksinya berasal dari wilayah tersebut atau tidak. Pendapatan yang timbul oleh adanya kegiatan produksi tersebut merupakan pendapatan domestik. Sedangkan yang dimaksud dengan wilayah domestik atau region adalah meliputi wilayah yang berada di dalam wilayah geografis region tersebut. ${ }^{1}$ Menurut BPS (2010) Produk Domestik Regional Bruto (PDRB) merupakan

h. 1

${ }^{1}$ Rudy Badrudin. Pengantar IImu Ekonomi, Ed. 1, (Dosen Luar Biasa FISIP UAJY), 
nilai tambah bruto seluruh barang dan jasa yang tercipta atau dihasilkan di wilayah domestik suatu negara yang timbul akibat berbagai aktivitas ekonomi dalam suatu periode tertentu tanpa memperhatikan apakah faktor produksi yang dimiliki residen atau non-residen. ${ }^{2}$

PDRB menggambarkan kenaikan dan penurunan tingkat pendapatan masyarakat di daerah tersebut yaitu Kenaikan atau penurunan riil, kenaikan atau penurunan tingkat pendapatan yang tidak dipengaruhi oleh perubahan harga. Apabila terjadi kenaikan riil tingkat pendapatan penduduk berarti daya beli penduduk di daerah tersebut meningkat. ${ }^{3}$

Dalam PDRB terdapat 17 sektor yang mempengaruhi diantaranya Pertanian, Kehutanan, dan Perikanan, Pertambangan dan Penggalian, Industri Pengolahan, Pengadaan Listrik dan Gas, Pengadaan Air, Konstruksi, Perdagangan Besar dan Eceran; Reparasi dan Perawatan Mobil dan Sepeda Motor, Transportasi dan Pergudangan, Penyediaan Akomodasi dan Makan Minum, Informasi dan Komunikasi, Jasa Keuangan, Administrasi Pemerintahan, Pertahanan dan Jaminan Sosial Wajib, Jasa Pendidikan, Jasa Kesehatan dan Kegiatan Sosial, Jasa Lainnya. ${ }^{4}$ Berdasarkan latar belakang di atas, maka penulis dapat menarik rumusan masalah sebagai berikut: Apakah Produk Domestik Regional Bruto atas dasar harga konsatan Berpengaruh Pada Pendapatan Masyarakat Kabupaten Bone tahun 2011-2015?

\footnotetext{
2Badan Pusat Statistik Kabupaten Bone 2016, Buku Publikasi Produk Domestik Regional Bruto Kabupaten Bone Menurut Lapangan Usaha 2011-2015.

${ }^{3}$ Robinson Taringan, Ekonomi Regional Teori dan Aplikasi Edisi Revisi, h. 20 ${ }^{4}$ Perubahan Tahun Dasar PDB Berbasis SNA 2008, h. 8
} 


\section{METODE}

1. Jenis Penelitian

Jenis penelitian ini merupakan penelitian lapangan. Adapun yang dimaksud dengan Field reseacrh (Penelitian Lapangan) yaitu penelitian yang dilakukan secara intensif, terperinci, dan mendalam terhadap suatu obyek yang di lapangan untuk memperoleh informasi dan data sesuai permasalahan penelitian. ${ }^{5}$ Dalam penelitian ini, jenis penelitian ini digunakan untuk mengetahuidampak Produk Domestik Regional Bruto atas dasar harga konstan terhadap Pendapatan Masyarakat Kabupaten Bone.

\section{Pendekatan Penelitian}

Penelitian ini menggunakan pendekatan kuantitatif, pendekatan yang digunakan untuk menguji suatu teori, untuk menunjukan hubungan antarvariabel, dan ada pula yang bersifat mengembangkan konsep, mengembangkan pemahaman serta dalam ilmu-ilmu alam maupun ilmu-ilmu sosial. ${ }^{6}$ Peneliti menggunakan pendekatan kuantitatif karena penelitian ini akan menghasilkan data-data yang telah diolah dan mendepenelitiankanya berupa kata-kata tertulis atau data dalam bentuk table atau grafik.

1. Lokasi, Populasi, dan Sampel
a). Lokasi

\section{h. 34}

${ }^{5}$ Supardi, Metodologi Penelitian Ekonomi dan Bisnis, (Cet. I: Yogyakarta: UII Press, 2005),

${ }^{6}$ Prasetyo Bambang, Metode Penelitian Kuantitatif: Teori dan Aplikasi, (Jakarta:RajaGrafindoPersada), h. 24 
Lokasi penelitian merupakan tempat yang dijadikan sebagai wilayah atau daerah penelitian. Lokasi dalam penelitian ini yaitu Dinas Pertanian dan Dinas Perikanan Kabupaten Bone, dan data kehutanan diambil dari Produk Domestik Regional Bruto Menurut Lapangan Usaha Kabupaten Bone 2011-2015. Alasan yang mendasari dijadikannya sebagai tempat penjaringan data bagi penelitian ini, yaitu: (1) SDM-nya profesional dan sepenuhnya mengerti bidangnya masing-masing, (2) Pelayanan memuaskan, (3) Data yang di butuhkan tersedia, dan (4) Tidak mengalami kesulitan dalam pengambilan data bagi penelitian ini.

b). Populasi

Populasi adalah wilayah generalisasi yang terdiri atas objek atau subjek yang memiliki kualitas dan karakteristik tertentu yang ditetapkan oleh peneliti untuk dipelajari dan kemudian ditarik kesimpulannya. ${ }^{7}$ Populasi dalam penelitian ini adalah semua data Produk Domestik Regional Bruto atas harga konstan yang terdiri dari tujuh belas sektor diantaranya Pertanian, Kehutanan, dan Perikanan, Pertambangan dan Penggalian, Industri Pengolahan, Pengadaan Listrik dan Gas, Pengadaan Air, Konstruksi, Perdagangan Besar dan Eceran; Reparasi dan Perawatan Mobil dan Sepeda Motor, Transportasi dan Pergudangan, Penyediaan Akomodasi dan Makan Minum, Informasi dan Komunikasi, Jasa Keuangan, Administrasi Pemerintahan, Pertahanan dan Jaminan Sosial Wajib, Jasa Pendidikan, Jasa Kesehatan dan Kegiatan Sosial, Jasa Lainnya. dan data Pendapatan Masyarakat Kabupaten Bone.

\footnotetext{
${ }^{7}$ Sugiyono, Metode Penelitian Bisnis (Cet. X; Bandung : CV Alfabeta, 2007), h. 72.
} 
c). Sampel

Sampel adalah bagian dari jumlah yang dimiliki oleh populasi. Teknik pengambilan dalam penelitian ini adalah menggunakan Porposive Sampling yaitu pengambilan sampel secara sengaja sesuai dengan persyaratan sample yang diperlukan. Adapun sampel dalam penelitian ini adalah data Pertanian, Kehutanan, dan Perikanan. Karena di Kabupaten Bone sektor Pertanian, Kehutanan, dan Perikanan yang paling unggul, berdasarkan data statistik lima tahun terakhir.

\section{Data dan Sumber Data}

Data merupakan bentuk jamak dari kata datum, yang berasal dari bahasa Latin. Data dapat diartikan sebagai fakta-fakta atau bisa dikatakan sebagai serangkaian bukti-bukti, sesuatu yang secara pasti diketahui atau serangkaian informasi yang ada di sekitar kita. ${ }^{8}$ Data dalam penelitian ini menggunakan jenis data skala rasio. Adapun sumber data yang digunakan dalam penelitian ini adalah data sekunder. Data sekunder ialah sumber data yang diperoleh secara langsung dari sumber asli (tidak melalui perantara media), terdiri dari dokumendokumen, surat, dokumen-dokumen resmi dari instansi pemerintah, laporan keuangan, dan lain sebagainya yang berupa arsip perusahaan. Data Primer yang digunakan dalam penelitian ini adalah data sektor Pertanian, Kehutanan, dan Perikanan.

\section{Variabel Penelitian}

${ }^{8}$ Muhammad Teguh, Metodologi Penelitian Ekonomi: Teori dan Aplikasi, (Ed. 1; Cet. 3; Jakarta: RajaGrafindo Persada, 2005), h. 118 
Variabel dapat didefinisikan sebagai konsep yang mewakili variasi atau mewakili lebih dari satu nilai. ${ }^{9}$ Variabel pada hakikinya merupakan konsep yang mempunyai variasi nilai; sedangkan konsep mempunyai satu nilai disebut dengan "constant". ${ }^{10}$ Dalam penelitian ini, variabel yang digunakan sebagai obyek utama dalam membahas permasalahan yang diangkat terdiri dari dua, yaitu:

a) Variabel bebas (independent variable) merupakan variabel yang memengaruhi variabel lain atau menhasilkan akibat pada variabel yang lain, yang pada umumnya berada dalam urutan tata waktu yang terjadi lebih dulu. Keberadaan variabel ini dalam penelitian kuantitatif merupakan variabel yang menjelaskan terjadinya fokus atau topik penelitian. Variabel ini biasanya disimbolkan dengan variabel " $x$ ". ${ }^{11}$ Adapun variabel bebas dalam penelitian ini yaitu Produk Domestik Regional Bruto atas dasar harga konstan.

b) Variabel terikat (dependent variable) merupakan variabel yang diakibatkan atau dipengaruhi oleh variabel bebas. Keberadaan variabel ini dalam penelitian kuantitatif adalah sebagai variabel yang dijelaskan dalam fokus atau topik penelitian. Variabel ini biasanya disimbolkan dengan variabel "y". ${ }^{12}$ Adapun variabel terikat dalam penelitian ini yaitu Pendapatan Masyarakat.

\section{Teknik Pengumpulan Data}

${ }^{9}$ Nanang Martono, Metode Penelitian Kuantitatif Ed. 2 (Cet. 5; Jakarta: Rajawali Pers, 2016), h. 59 .

${ }^{10}$ A. Muri Yusuf, Metode Penelitian: Kuantitatif, Kualitatif, dan Penelitian Gabungan Ed. 1 (Cet. 2; Jakarta: Kencana, 2015), h. 102.

${ }^{11}$ Nanang Martono, Metode Penelitian Kuantitatif h. 61.

${ }^{12}$ Nanang Martono, Metode Penelitian Kuantitatif h. 61. 
Dalam mengumpulkan data dalam penelitian ini yang digunakan adalah:

a) Observasi

Observasi atau pengamatan adalah kegiatan keseharian manusia dengan menggunakan pancaindra mata sebagai alat bantu utamanya selain pancaindra lainnya seperti telinga, penciuman , mulut, dan kulit. Oleh karena itu, observasi adalah kemampuan seseorang untuk menggunakan pengamatannya melalui hasil kerja pancaindra mata serta dibantu dengan pancaindra lainnya. ${ }^{13}$ Observasi digunakan untuk mengumpulkan data primer yang terdiri sektor Pertanian, Kehutanan, dan Perikanan di Kabupaten Bone.

b) Dokumentasi

Dokumentasi adalah proses pengumpulan data berupa data-data tertulis yang mengandung keterangan dan penjelasan serta pemikiran tentang fenomena yang masih akurat dan sesuai dengan masalah penelitian. ${ }^{14}$ Dokumentasi digunakan untuk mengumpulkan data primer yang terdiri data Pertanian, Kehutanan, dan Perikanan di Kabupaten Bone.

\section{Teknik Analisis Data}

Teknik analisis data merupakan cara menganalisis data penelitian, termasuk alat-alat statistik yang relevan untuk digunakan dalam penelitian. ${ }^{15}$ Dalam menganalisis data-data dalam penilitian ini,

\footnotetext{
${ }^{13}$ Burhan Bungin, Metedologi Penelitian Sosial \& Ekonomi h. 142.

${ }^{14}$ Suharsimi Arikunto, Prosedur Penelitian: Suatu Pengantar Praktek (Cet. 12; Jakarta: PT. Rineka Cipta, 2002), h. 108.

${ }^{15}$ Juliansyah Noor, Metedologi Penelitian, Ed. 1 (Cet. 4; Jakarta: Kencana, 2014), h. 162
} 
tekhnik analisis yang akan digunakan adalahmetode deskriptifdan fungsi linear dengan model the simple linear model in two variables and its extensions. ${ }^{16}$ Metode deskriptif merupakan suatu prosedur pemecahan masalah dengan menggambarkan atau melukiskan keadaan subjek/objek penelitian berdasarkan fakta-fakta yang tampak, serta sebagai suatu langkah untuk mendepenelitiankan fakta tentang gejalagejala yang terdapat di dalam masalah yang diselidiki. ${ }^{17}$ Dalam menganalisis data-data dalam penilitian ini, tekhnik analisis yang akan digunakan adalah regresi linier sederhana. Analisis regresi linier sederhana adalah hubungan secara linier antara satu variabel independen $(X)$ dengan variabel dependen $(Y)$. Analisis ini untuk mengetahui arah hubungan antara variabel indevenden dengan variabel dependen apakah berdampak atau tidak berdampak dan untuk memprediksi nilai dari variabel dependen apabila nilai variabel independen mengalami kenaikan atau penurunan. Adapun rumus regresi linier

\section{HASIL DAN PEMBAHASAN}

Berdasarkan hasil analisis yang telah diuraikan di atas, diperoleh hasil bahwa variabel X PDRB berdampak terhadap variabel $Y$ Pendapatan Masyarakat (PM) di Kabupaten Bone. Hal tersebut ditunjukkan dari hasil analisis Person Correlation atau Korelasi Product Moment (KPM) sebesar 0,303 dibandingkan dengan $r_{\text {tabel }}$ tingkat signifikan $5 \% \mathrm{~N}=5$ sebesar 0,950. Jadi $r_{\text {hitung }}<r_{\text {tabel, }}$ maka dapat ditarik bahwa hipotesis nol $\left(\mathrm{H}_{0}\right)$ ditolak dan $\left(\mathrm{H}_{\mathrm{a}}\right)$ diterima. Dengan koefisien determinasi sebesar $9,2 \%$ atau dibulatkan

\footnotetext{
${ }^{16}$ Ghosh Sukesh K, Econometrics: Theory and Applications, h. 14

${ }^{17}$ Hadari Nawawi, Metode Penelitian bidang Sosial, (Cet. 9; Yogyakarta: Gajah Mada University Press, 2001), h. 63
} 
menjadi 9\%menunjukkan bahwa variabel bebas $X$ memiliki dampak kontribusi sebesar $9,2 \%$ atau $9 \%$ terhadap variabel $Y$.

Sedangkan dari hasil uji t diketahui bahwa terdapat dampak variabel $\mathrm{X}$ terhadap variabel $\mathrm{Y}$. Dengan hasil analisis uji t sebesar 0,551, sedangkan tabel 3,182 pada taraf signifikan $5 \%$ yang berarti bahwa $\mathrm{H}_{\mathrm{a}}$ diterima. Selain itu juga diperoleh persamaan regresi $Y=0,984+0,372$. Sehingga hasil uji $t$ terdapat dampak secara signifikan antara variabel $X$ terhadap variabel $\mathrm{Y}$.

Konstanta (a) sebesar 0,984: artinya jika PDRB (X) nilainya adalah 0, maka Pendapatan Masyarakat $(Y)$ sebesar 0,984. Koefisien regresi variabel PDRB sebesar 0,372: artinya jika PDRB (X) mengalami peningkatan kenaikan 1, maka Pendapatan Masyarakat (Y),akan mengalami peningkatan sebesar 0,372. Koefisien berfisat positif artinya terjadi dampak antara variabel PDRB $(X)$ dan variabel Pendapatan Masyarakat $(Y)$, semakin naik PDRB maka semakin meningkat Pendapatan Masyarakat.

\section{Grafik. 1.Pendapatan Masyarakat (PM) 2011-2015}

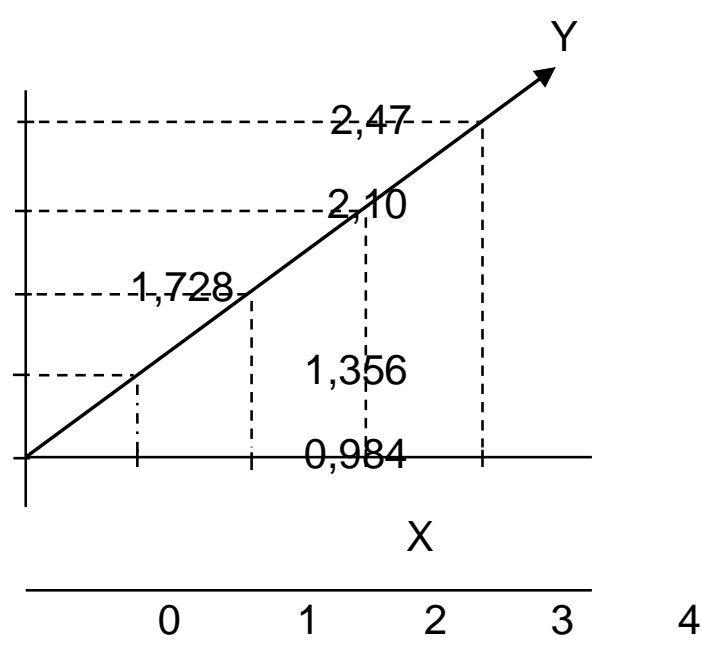


Berdasarkan grafik diatas, maka dapat dilihat bahwa $Y$ disimbolkan sebagai Pendapatan Masyarakat dan X sebagai PDRB, dimana jika PDRB berada pada titik 0 maka Pendapatan Masyarakat sebesar 0,984, tapi jika PDRB naik 1\% maka tingkat Pendapatan Masyarakat sebesar 1,356. Demikian pula hingga kenaikan $4 \%$, dimana pada kenaikan $4 \%$ maka tingkat Pendapatan Masyarakat sebesar 2,47.

\section{KESIMPULAN DAN SARAN}

1. Kesimpulan

Berdasarkan hasil analisis dan pembahasan terhadap permasalahan yang diungkapkan dan guna pembuktian hipotesa yang telah dipaparkan pada sebelumya, maka dapat ditarik kesimpulan, sebagai berikut:

Produk Domestik Regional Bruto (PDRB) Berdasarkan Harga Konstan Berdampak terhadap Pendapatan Masyarakat, berdasarkan hasil ini menunjukkan bahwa PDRB sektor Pertanian, Perkebunan, dan Perikanan berperan dalam meningkat pendapatn masyarakat dalam bidang Pertanian, Perkebunan, dan Perikanan di kabupaten bone hal ini ditunjukan pada setiap kenaikan PDRB maka Pendapatan Masyarakat juga naik. Dimana kenaikan 1\% PDRB, maka Pendapatan Masyarakat (Y) akan mengalami peningkatan sebesar 0,372 menjadi 1,356 begitupun juga jika PDRB berada pada 4\% Pendapatan Masyarakat sebanyak 2,47\%.

2. Saran

Berdasarkan kesimpulan di atas, maka penulis memberikan saransaran sebagai berikut: 
Pemerintah dan dinas-dinas terkait agar memperhatikan masyarakat yang bekerja sebagai petani, pekebun, dan nelayan, mengingat ketiganya yang berperan dalam menyokong peningkatan PDRB di Kabupaten Bone, apabila PDRB sektoral meningkat maka Pendapatan Masyarakat (petani, pekebun, dan nelayan) juga akan meningkat, dan apa bila Pendapatan Masyarakat (petani, pekebun, dan nelayan) meningkat maka masyarakat (petani, pekebun, dan nelayan) semakin sejahtera.

\section{DAFTAR PUSTAKA}

Andi Posman Simamora, dkk. "Analisis Potensi Sektor Pertanian terhadap Pengembangan Wilayah di Kabupaten Humbang Hasundutan", Jurnal Ekonom, Vol 16, No 2, Alumni PWD SPs USU dan Dosen FE/FP/PWD SPs USU, 2013.

Arikunto, Suharsimi. Prosedur Penelitian: Suatu Pengantar Praktek, Cet. 12; Jakarta: PT. Rineka Cipta, 2002.

Aziz, Abdul. Ekonomi Islam Analisis Mikro dan Makro, Ed. 1, Cet. 1; Yogyakarta: Graha IImu, 2008.

Badan Pusat Statistik Kabupaten Bone 2016, Buku Publikasi Produk Domestik Regional Bruto Kabupaten Bone Menurut Lapangan Usaha 2011-2015.

Badan Pusat Statistik Kabupaten Purbalingga, Produk Domestik Regional Bruto Kabupaten Purbalingga Menurut Lapangan Usaha 2010-2014.

Badrudin, Rudy. Pengantar Ilmu Ekonomi, Ed. 1, (Dosen Luar Biasa FISIP UAJY). 
Bambang. Prasetyo. Metode Penelitian Kuantitatif: Teori dan Aplikasi, Jakarta: RajaGrafindo Persada.

Boediono, Pengantar Ekonomi, Jakarta: Erlangga, 2002.

Bungin, Burhan. Metedologi Penelitian Sosial \& Ekonomi, Ed. 1, Cet. 2; Jakarta: Kencana, 2015.

Danil, Mahyu. "Pengaruh Pendapatan Terhadap Tingkat Konsumsi pada Pegawai Negeri Sipil di Kantor Bupati Kabupaten Bireuen", Journal Ekonomika Universitas Almuslim Bireuen Aceh, Vol. IV No. 7:9.

Departemen Pendidikan dan Kebudayaan, Kamus Besar Bahasa Indonesia, Jakarta: Balai Pustaka, 1998.

Departemen Statistik Ekonomi dan Moneter, Bank Indonesia, Produk Domestik Regional Bruto (PDRB), Jakarta.

Guritno Mangkoesoebroto dan Algifari, Teori Ekonomi Makro, STIE YPKN, Yogyakarta, 1998.

Makdalena F Asmuruf, dkk. "Pengaruh Pendapatan Dan Jumlah Penduduk terhadap Pendapatan Asli Daerah ( PAD ) di Kota Sorong", Jurnal Berkala Ilmiah Efisiensi, Universitas Sam Ratulangi, Manado, 2015.

Marbun, BN. Kamus Manajemen, Jakarta: Pustaka Sinar Harapan, 2003.

Martono, Nanang. Metode Penelitian Kuantitatif Ed. 2, Cet. 5; Jakarta: Rajawali Pers, 2016.

Muctholifa,"Pengaruh Domestik Regional Bruto (PDRB), Inflasi, Investasi dan Jumlah Tenaga Kerja Terhadap Pendapatan Asli Daerah (PAD) di Kota Mojokerto", Jurnal Ilmu Ekonomi Pembangunan, Vol. 1, No. 1, Januari 2010. 
Nasution, S. Metode Research; Penelitian IImiah, Cet. III; Jakarta : PT Bumi Aksara, 2000.

Nawawi, Hadari. Metode Penelitian bidang Sosial, Cet. 9; Yogyakarta: Gajah Mada University Press, 2001.

Noor, Juliansyah. Metedologi Penelitian, Ed. 1, Cet. 4; Jakarta: Kencana, 2014.

Perubahan Tahun Dasar PDB Berbasis SNA 2008.

prayitno, Rekso. Sistem Ekonomi dan Demokrasi Ekonomi, Jakarta: Bina Grafika, 2004.

Sugiyono, Metode Penelitian Bisnis, Cet. X ; Bandung : CV Alfabeta, 2007.

Sukirno, Sadono. Teori Pengantar Mikro Ekonomi, Jakarta: Rajagrafindo Persada, 2006. 
